\title{
Long-term safety and efficacy of etanercept in the treatment of ankylosing spondylitis
}

This article was published in the following Dove Press journal:

Patient Preference and Adherence

20 September 2013

Number of times this article has been viewed

José Miguel Senabre-

Gallego'

Carlos Santos-Ramírez ${ }^{2}$

Gregorio Santos-Soler'

Esteban Salas-Heredia'

Mabel Sánchez-

Barrioluengo ${ }^{3}$

Xavier Barber ${ }^{4}$

José Rosas'

\section{On behalf of the AIRE-MB group}

'Rheumatology, Hospital Marina Baixa, Villajoyosa, ${ }^{2}$ Rheumatology, Hospital Marina Salud, Denia, ${ }^{3}$ INGENIO (Instituto de Gestión de la Inovación y del Conocimiento) (CSIC [Consejo Superior de Investigaciones Científicas]-UPV [Universidad Politécnica de Valencia]), Universitat Politècnica de València, Valencia, ${ }^{4} \mathrm{ClO}$ (Centro de Investigación Operativa)-UMH (Universidad Miguel Hernández), Universidad Miguel Henández, Elche, Spain
Correspondence: José Miguel Senabre-Gallego

Rheumatology Unit, Hospital Marina Baixa, Av Alcalde Jaume Botella Mayor 7, 03570 Villajoyosa, Alicante, Spain Email senabre@hotmail.es
Abstract: To date, anti-tumor necrosis factor alfa (anti-TNF- $\alpha$ ) therapy is the only alternative to nonsteroidal anti-inflammatory drugs for the treatment of ankylosing spondylitis. Etanercept is a soluble TNF receptor, with a mode of action and pharmacokinetics different to those of antibodies and distinctive efficacy and safety. Etanercept has demonstrated efficacy in the treatment of ankylosing spondylitis, with or without radiographic sacroiliitis, and other manifestations of the disease, including peripheral arthritis, enthesitis, and psoriasis. Etanercept is not efficacious in inflammatory bowel disease, and its efficacy in the treatment of uveitis appears to be lower than that of other anti-TNF drugs. Studies of etanercept confirmed regression of bone edema on magnetic resonance imaging of the spine and sacroiliac joint, but failed to reduce radiographic progression, as do the other anti-TNF drugs. It seems that a proportion of patients remain in disease remission when the etanercept dose is reduced or administration intervals are extended. Etanercept is generally well tolerated with an acceptable safety profile in the treatment of ankylosing spondylitis. The most common adverse effect of etanercept treatment is injection site reactions, which are generally self-limiting. Reactivation of tuberculosis, reactivation of hepatitis $\mathrm{B}$ virus infection, congestive heart failure, demyelinating neurologic disorders, hematologic disorders like aplastic anemia and pancytopenia, vasculitis, immunogenicity, and exacerbation or induction of psoriasis are class effects of all the anti-TNF drugs, and have been seen in patients with ankylosing spondylitis. However, etanercept is less likely to induce reactivation of tuberculosis than the other anti-TNF drugs and it has been suggested that etanercept might be less immunogenic, especially in ankylosing spondylitis. Acute uveitis, Crohn's disease, and sarcoidosis are other adverse events that have been rarely associated with etanercept therapy in patients with ankylosing spondylitis.

Keywords: ankylosing spondylitis, etanercept, spondyloarthritis, efficacy, safety

\section{Introduction}

Spondyloarthritis refers to a heterogeneous group of diseases that share clinical, pathogenic, and hereditary features, and include ankylosing spondylitis (AS) and psoriatic arthritis. The spondyloarthritides are characterized by chronic inflammation of the enthesis with a tendency to bone ankylosis. The most frequent clinical features are sacroiliitis, enthesitis, iritis, oligoarthritis, psoriasis, and inflammatory bowel disease. ${ }^{1}$

The prevalence of spondyloarthropathy is estimated to be between $0.1 \%$ and $2.5 \%$, although figures vary from one study to another. The reported incidence ranges from 0.3 to $7.3 / 100,000$ inhabitants per year. ${ }^{2}$ The impact on quality of life can be very negative, given that pain and functional disability affect patients both physically and psychologically. 
Nonsteroidal anti-inflammatory drugs and physical exercise have been the cornerstone of treatment for spondyloarthritis, but are not effective in some cases. Other disease-modifying antirheumatic drugs (DMARDs) like sulfasalazine, methotrexate, or leflunomide, are recommended for treating peripheral arthritis or extra-articular features. However, in cases of exclusive spinal involvement that do not respond to nonsteroidal anti-inflammatory drugs, the only option to date is to use anti-tumor necrosis factor (TNF) drugs. Since the advent of anti-TNF drugs, the symptoms of spondyloarthritis have improved dramatically. Further, their use has been linked to the clearing of active lesions on magnetic resonance imaging (MRI), such as bone edema, but the studies published to date have not demonstrated prevention of structural damage. ${ }^{3}$

The primary target of treatment is remission of the disease and, when that fails, to minimize inflammatory activity, to improve the signs and symptoms of spondyloarthritis, and to prevent structural damage and functional disability, thus safeguarding the patient's quality of life. Therefore, persistence of activity indicates the need for a change of treatment.

The Assessment of Spondyloarthritis International Society (ASAS) recommends use of anti-TNF in patients diagnosed with AS or spondyloarthritis if they have active disease and have not improved with conventional treatment. ${ }^{4}$ Currently, there are four anti-TNF agents approved for spondyloarthritis, including three monoclonal antibodies, ie, infliximab, adalimumab, and golimumab, and a soluble TNF receptor, etanercept. All four have efficacy demonstrated in randomized clinical trials, with significant superiority over placebo and about $60 \%$ of patients reaching an ASAS 20 response versus $20 \%$ of patients assigned to placebo.

Etanercept is composed of two recombinant forms of the human TNF receptor P75 fused to an Fc portion of human immunoglobulin G1, and is administered subcutaneously $50 \mathrm{mg}$ a week or $25 \mathrm{mg}$ twice a week. It has a differences regarding way of action and pharmacokinetics, what implies differences with antibodies in effectiveness and safety.

In this paper, we review the efficacy and safety of etanercept in the treatment of AS, and how it differs from the other anti-TNF drugs reported in the literature.

\section{Efficacy of etanercept in ankylosing spondylitis Efficacy outcome measures used in the studies}

Disease activity in patients with AS has been evaluated using the Bath Ankylosing Spondylitis Disease Activity Index ${ }^{5}$
(BASDAI), physical function using the Bath Ankylosing Spondylitis Functional Index ${ }^{6}$ (BASFI), and mobility by the Bath Ankylosing Spondylitis Metrology Index ${ }^{7}$ (BASMI).

In 2001, the ASAS developed outcome measures recommended for use in trials of symptom-modifying therapy. ${ }^{8}$ The ASAS 20 improvement criteria summarize changes in the domains of physical function, pain, patient global assessment, and inflammation. A positive response is defined as a $20 \%$ or greater improvement and a net improvement of one unit on a 10-unit scale in each of three domains, with no worsening in the fourth. An ASAS 40 response is defined as $\geq 40 \%$ improvement of at least two units in each of three domains, with no worsening in the fourth. ASAS partial remission is defined as a score below two units in each domain, and ASAS $5 / 6$ is defined as $20 \%$ improvement in five of six domains, adding C-reactive protein and lateral vertebral flexion.

More recently, the ASAS association has validated the Ankylosing Spondylitis Disease Activity Score, ${ }^{9}$ that includes C-reactive protein levels in addition to some of the BASDAI questions and is a highly discriminatory instrument for assessing disease activity in AS.

\section{Efficacy in ankylosing spondylitis}

The efficacy of etanercept in AS has been assessed in several randomized clinical trials (Table 1). The first to evaluate the efficacy of etanercept in AS was published in 2002, with 40 active AS patients randomly assigned to receive etanercept $25 \mathrm{mg}$ twice weekly or placebo for 4 months. ${ }^{10}$ The intention-to-treat analysis revealed an ASAS 20 rate of $80 \%$ in the etanercept group versus $30 \%$ in the placebo group $(P=0.004)$. Significant improvement was achieved in four of the five measures of ASAS 20. The treatment arm also showed significantly greater improvement in many of the secondary outcome measures (physician's global assessment of disease activity, chest expansion, erythrocyte sedimentation rate, and C-reactive protein level). Patients in the placebo group were treated with etanercept in a 6-month, open-label extension of the trial, with a rapid response and no statistically significant differences in efficacy from patients treated with etanercept throughout the entire 10-month period. ${ }^{11}$

In June 2003, a multicenter randomized clinical trial including 30 patients with active AS was published. ${ }^{12}$ In the first phase of the study, patients were randomized to receive either etanercept $25 \mathrm{mg}$ twice weekly $(\mathrm{n}=14)$ or placebo $(n=16)$ for 6 weeks. Nonsteroidal anti-inflammatory drugs were permitted, but steroids and DMARDs had to be stopped prior to the study. The primary outcome parameter $(>50 \%$ improvement on BASDAI) was achieved by $57 \%$ of the 
Table I Main randomized clinical trials analyzing the efficacy of etanercept in ankylosing spondyloarthritis

\begin{tabular}{|c|c|c|c|c|c|c|}
\hline Reference & Year & Type & $\mathbf{n}$ & Duration (weeks) & Endpoints & $P$ \\
\hline Gorman et al ${ }^{10}$ & 2002 & $\mathrm{RCT}$ & $20 / 20$ & 16 & ASAS 20 & 0.004 \\
\hline Davis et al" & & OLE & 17 & 40 & & \\
\hline \multirow[t]{2}{*}{ Brandt et al ${ }^{12,13}$} & 2003 & RCT & $14 / 16$ & 6 & BASDAI 50, ASAS 20, BASDAI, & 0.004 \\
\hline & & OLE & 23 & 54 & BASFI, BASMI & \\
\hline \multirow[t]{2}{*}{ Davis et al $\left.\right|^{14,15}$} & 2003 & $\mathrm{RCT}$ & $138 / 139$ & 24 & ASAS 20 & 0.0001 \\
\hline & & OLE & $128^{*}$ & 192 & & \\
\hline Calin et $\mathrm{al}^{16}$ & 2004 & RCT & $45 / 39$ & 12 & ASAS $20,40,5 / 6$, BASDAI & 0.001 \\
\hline Dijkmans et $\mathrm{al}^{17}$ & & OLE & 43 & 96 & & \\
\hline van der Heijde et al ${ }^{18}$ & 2006 & $\mathrm{RCT}$ & $305 / 51$ & 12 & ASAS $20,40,5 / 6$ & 0.001 \\
\hline Braun et $\mathrm{al}^{19}$ & 2007 & $\mathrm{RCT}$ & $305 / 51$ & 12 & BASFI, EuroQOL-5D, SF-36 & 0.001 \\
\hline Braun et $\mathrm{a}^{20}$ & 2011 & RCT & $379 / 187$ & 16 & $\begin{array}{l}\text { ASAS } 20,40,5 / 6 \text {, BASDAI, } \\
\text { BASFI, BASMI }\end{array}$ & 0.0001 \\
\hline Li et $\mathrm{al}^{21}$ & 2013 & MET & I,570 & - & $\begin{array}{l}\text { ASAS } 20,40,5 / 6 \text {, partial remission, } \\
\text { BASFI, BASDAI, BASMI }\end{array}$ & 0.00001 \\
\hline
\end{tabular}

Note: *Includes only patients receiving ETN from the beginning of the study.

Abbreviations: ASAS, Assessment of Spondyloarthritis International Society; ETN, etanercept; MET, meta-analysis; OLE, open-label extensions; RCT, randomized clinical trial; BASFI, Ankylosing Spondylitis Functional Index; BASDAI, Bath Ankylosing Spondylitis Disease Activity Index; BASMI, Bath Ankylosing Spondylitis Metrology Index.

etanercept group versus $6 \%$ of the placebo group $(P=0.004)$. An ASAS 20 response was achieved by $78.6 \%$ versus $25 \%$ of patients, respectively. Similarly, pain, physical function, mobility, quality of life, and scores on BASDAI, BASFI, and BASMI improved significantly. In the second phase of the study, both groups (placebo and etanercept) were treated with etanercept for 12 weeks, and $56 \%$ of patients in the placebo group achieved a $>50 \%$ improvement in BASDAI score. After 12 weeks of treatment, all patients discontinued etanercept, and $75 \%$ experienced a relapse in a mean of 27 weeks. These patients were eligible to restart etanercept in a 54-week, open-label extension trial. ${ }^{13}$ The intention-to-treat analysis showed that $57.7 \%$ of patients achieved a $50 \%$ improvement in the BASDAI, and $73.1 \%$ were responders using the ASAS 20 criteria. This confirms that readministration of etanercept is efficacious and safe in AS patients.

Another multicenter randomized clinical trial in 2003 assessed the efficacy of etanercept in $277 \mathrm{AS}$ patients. ${ }^{14}$ In the first 24-week, double-blind trial, patients were randomized to receive etanercept $25 \mathrm{mg}$ or placebo twice weekly. The primary outcome measure, ASAS 20, was achieved by $59 \%$ of patients in the active treatment group and by $28 \%$ of patients in the placebo group at week 12 , and by $57 \%$ and $22 \%$ patients, respectively, at week 24 , with a statistically significant difference between the groups. ASAS 50 and 70 responses were achieved in $40 \%$ and $20 \%$ of etanercept patients, respectively. In an open-label extension of this study, 257 patients received etanercept for 168 weeks. ${ }^{15}$ The patients who had received etanercept in the double-blind trial had a sustained response, with $71 \%$ achieving an ASAS 20 at week 96 and $81 \%$ at week 192. Patients who switched to etanercept in the open-label extension had similar responses, with $70 \%$ attaining an ASAS 20 at week 24, 78\% at week 72 , and $82 \%$ at week 168 .

In 2004, another multicenter randomized clinical trial was performed in Europe, with 45 patients randomly assigned to etanercept $25 \mathrm{mg}$ and 39 to placebo twice weekly for 12 weeks. ${ }^{16}$ Significantly more patients were ASAS 20 responders in the etanercept group (60\% versus $23 \%$, respectively). ASAS 50 and ASAS 70 responses were achieved by $49 \%$ and $24 \%$ of patients in the etanercept group, respectively. Simultaneous significant improvement of functional status and metrology were observed. A 96-week, open-label extension of this study with 81 patients confirmed the improvement, with $83 \%$ of ASAS 20 responders in the etanercept/etanercept group and $74 \%$ in the placebo/etanercept group. ${ }^{17}$

In 2006, a 12-week randomized clinical trial compared the efficacy of etanercept $50 \mathrm{mg}$ once weekly with that of etanercept $25 \mathrm{mg}$ twice weekly and placebo in 365 patients with AS. ${ }^{18}$ Similar discontinuation rates were found between the etanercept groups. ASAS 20 response rates were higher in patients on etanercept compared with those on placebo (74.2\%, 71.3\%, and $37.3 \%$, respectively, $P=0.001)$. Similar results were found when analyzing ASAS 5/6, ASAS 40, and other measures of disease activity. The incidence of adverse events was similar between the three groups. The same doses were compared further in a 12 -week randomized clinical trial that assessed patient-reported outcomes in 356 AS patients. ${ }^{19}$ Treatment with etanercept $50 \mathrm{mg}$ once weekly or $25 \mathrm{mg}$ twice weekly significantly improved quality of life and functional status compared with placebo. These studies 
indicate that both doses of etanercept have comparable levels of efficacy in AS.

In 2011, ASCEND (an open-label, multicentre, supplementary extension study of etanercept in subjects with ankylosing spondylitis) compared the efficacy of etanercept and sulfasalazine in 566 biologic-naïve AS patients..$^{20}$ Because the patients included had to be candidates for treatment with sulfasalazine, most had peripheral arthritis (70\% in the etanercept group and $74 \%$ in the sulfasalazine group), and some had already tried DMARDs (28\% in both groups). Patients were randomized to receive etanercept $50 \mathrm{mg}$ once weekly or sulfasalazine (maximum $3 \mathrm{~g} /$ day) for 16 weeks. The proportion of ASAS 20 responders was significantly greater in the etanercept group as compared with the sulfasalazine group (76\% versus $53 \%, P<0.0001)$.

Finally, a recent meta-analysis that included 1,570 participants has investigated the efficacy of etanercept in Caucasian versus Chinese populations. ${ }^{21}$ Nine of the 14 randomized clinical trials included the ASAS 20 criteria, which was achieved by $72 \%$ of patients in the etanercept group versus $28 \%$ in the placebo group $(P<0.00001)$, with no significant heterogeneity between the studies. Similar results were found for ASAS 40, ASAS 5/6, ASAS partial remission, BASFI, BASDAI, BASMI, and patient global assessment. In addition, etanercept was effective in relieving total back pain, nocturnal pain, and morning stiffness, although no difference was found in improving chest expansion, occiputto-wall distance, and tender or swollen joint scores. Further, they found that, compared with the Chinese population, the Caucasian population showed higher rates of ASASA 40 and ASAS partial remission, and a higher incidence of treatmentemergent adverse events. ${ }^{21}$

\section{Comparative efficacy between anti-TNF therapies}

The efficacy of the four anti-TNF drugs available for AS has not been directly compared in randomized clinical trials. Indirect comparisons are limited and do not show a significant difference in effectiveness between them. ${ }^{22}$ Survival rates extracted from national registries have been used as a surrogate marker of efficacy, but controversial results have been reported. Data from the Austrian national register show better 2-year survival rates with etanercept than with adalimumab or infliximab, ${ }^{23}$ while the Danish national register shows no statistically significant differences between the three drugs. ${ }^{24}$ Overall drug survival for patients with rheumatoid arthritis, psoriatic arthritis, or AS was better for etanercept than for infliximab or adalimumab in the Norwegian registry, ${ }^{25}$ but this difference no longer exists when analyzing only first anti-TNF treatments. In the Czech registry, ${ }^{26}$ there were no differences in survival rates between the anti-TNF agents, although the difference between etanercept and infliximab was near statistical significance $(P=0.057)$. In addition, they found a higher proportion of patients with BASDAI $<4$ in the etanercept group than in the infliximab group.

\section{Efficacy as second-line anti-TNF therapy}

Although biologic therapy can provide rapid improvement in AS symptoms, some patients may not respond to their first anti-TNF drug and other patients may worsen over time. This observation, along with treatment withdrawal due to adverse events, makes switching between anti-TNF drugs common in everyday clinical practice. Efficacy on switching to a second anti-TNF drug has been evaluated in observational studies, with good response rates. ${ }^{27}$

Few studies have assessed the efficacy of etanercept in patients who have failed to respond to previous biologic therapy. Switching from infliximab to etanercept has been evaluated in two observational studies, and reported good clinical response rates. ${ }^{28,29}$

\section{Efficacy in axial spondyloarthritis without radiographically defined sacroiliitis}

Recently, new ASAS classification criteria for axial spondyloarthritis have been published, covering both patients with and without radiographic sacroiliitis. ${ }^{30}$ ABILITY (A Multicenter Study of the Efficacy and Safety of the Human Anti-TNF Monoclonal Antibody Adalimumab in Subjects With Axial Spondyloarthritis) demonstrated the efficacy of adalimumab in reducing disease activity in these patients, ${ }^{31}$ and before these criteria were ready infliximab also demonstrated good clinical efficacy in AS patients without radiographic sacroiliitis. ${ }^{32}$

The efficacy of etanercept in patients with preradiographic AS that fulfilled ASAS axial criteria was assessed in the ESTHER (effects of etanercept versus sulfasalazine in early axial spondyloarthritis on active inflammatory lesions as detected by whole-body magnetic resonance imaging) trial comparing etanercept with sulfasalazine. ${ }^{33}$ At week 48 , reduction of edema in the sacroiliac joint on whole-body MRI was significantly greater in the etanercept group than in the sulfasalazine group. In addition, there was a reduction in most clinical variables, and $50 \%$ of patients in the etanercept group reached clinical remission. 
Another randomized clinical trial with ASAS axial patients, that has not yet been published, found a better ASAS 40 response in the etanercept group versus placebo $(32.4 \%$ versus $15.7 \%, P<0.01) .{ }^{34}$

\section{Efficacy in severe long-standing disease}

The effect of etanercept in long-standing active AS was analyzed in a multicenter, 12-week, randomized clinical trial with 82 anti-TNF-naïve patients. The patients had to have radiologic intervertebral bridges or spine fusion and a BASDAI $>4$. This study reported greater improvement on BASDAI (area under the curve between baseline and week $12)$ in the etanercept group $(-19.8 \pm 16.5$ versus $-11.0 \pm 16.4$, $P=0.019) .{ }^{35}$ In a 12 -week, open-label extension of the trial, a significant decrease in nonsteroidal anti-inflammatory drug intake was found in the etanercept group. ${ }^{36}$

\section{Efficacy in hip lesions, peripheral joints, and extra-articular manifestations}

As previously noted, the most frequent clinical features of AS are sacroiliitis, enthesitis, iritis, oligoarthritis, psoriasis, and inflammatory bowel disease. The efficacy of etanercept in enthesitis was demonstrated by the ESTHER trial in patients with preradiographic AS on the basis of reduction of bone marrow edema on MRI at 27 enthesitic sites, including facet joints, costovertebral joints, and spinous processes. ${ }^{33}$ Etanercept is efficacious in the treatment of psoriasis $^{37}$ and psoriatic arthritis, ${ }^{38,39}$ but no benefit was observed in the treatment of inflammatory bowel disease.$^{40} \mathrm{In}$ a recent randomized clinical trial, etanercept was more effective than sulfasalazine in reducing the number of swollen joints in AS patients. ${ }^{41} \mathrm{In}$ one observational study, etanercept was able to alleviate hip symptoms in patients who had not responded to conventional therapy. ${ }^{42}$ The efficacy of etanercept in preventing flare-up of anterior uveitis is reviewed elsewhere in this article.

\section{Reduction of inflammation on MRI and radiographic progression}

Reduction of inflammation in AS patients by etanercept is also confirmed as regression of bone edema assessed by spinal MRI ${ }^{43,44}$ Nevertheless, radiographic progression has been analyzed in several trials with controversial results. Most of the studies that evaluated radiographic progression used the modified Stoke Ankylosing Spondylitis Spine Score (mSASSS) method. ${ }^{45}$ In a previously discussed trial, most patients had no radiographic progression using the mSASSS method at 60 weeks. ${ }^{17}$ However, in another 2-year randomized clinical trial, no differences in radiographic progression were found when comparing etanercept-treated patients with an anti-TNFnaïve cohort. ${ }^{3}$ Similarly negative findings were obtained with infliximab ${ }^{46}$ and adalimumab, ${ }^{47}$ leading to the suggestion that structural progression in AS is independent of TNF.

\section{High-dose efficacy}

In 2011, a 12-week, randomized clinical trial evaluated the efficacy of etanercept $50 \mathrm{mg}$ once weekly versus twice weekly in 108 AS patients who had previously failed standard therapies. No significant differences were found in any efficacy endpoint between the treatment groups. ${ }^{48}$

\section{Dose-tapering, extending intervals, or drug discontinuation}

Biologic drugs are an expensive therapy and a heavy economic burden for health care systems in many countries. Dose-tapering, extending intervals of administration, and drug discontinuation in patients in clinical remission are currently common practices with biologic therapy since they serve to curb health care costs. The efficacy of these practices has been assessed in several open-label studies.

Dose-tapering and interruption of etanercept was analyzed in a prospective uncontrolled trial with active AS biologic-naïve Korean patients. ${ }^{49}$ Treatment with etanercept $50 \mathrm{mg}$ once weekly was given for 3 months, and the dose was then tapered to $25 \mathrm{mg}$ once a week for 6 months, and finally discontinued. In the first 3 months, four (14.8\%) of 27 patients dropped out because of lack of response, and one patient relapsed and five patients were lost to follow-up on $25 \mathrm{mg}$ maintenance therapy. After discontinuation, $67 \%$ of patients relapsed within 9 weeks.

In the aforementioned ESTHER trial, $8 \%$ of patients with axial spondyloarthritis treated with etanercept for one year remained in permanent drug-free remission during the year versus $3 \%$ of patients in the sulfasalazine group, but this difference was not statistically significant. ${ }^{50}$ The efficacy of readministration of etanercept after treatment discontinuation was assessed in a previously discussed study with good results. ${ }^{13}$ Extending dosing intervals was assessed by another retrospective Korean analysis of 109 AS patients treated with etanercept. ${ }^{51}$ Patients started etanercept $25 \mathrm{mg}$ twice weekly and the dosing interval gradually increased to $4.7 \pm 2.1$ days at 3 months, $8.5 \pm 4.9$ days at 9 months, $9.9 \pm 5.8$ days at 15 months, and $12.1 \pm 7.0$ days at 21 months. BASDAI decreased from 8.5 to 0.6 at 21 months.

A very recent randomized prospective study evaluated the proportion of patients with AS maintaining clinical remission after extending etanercept $50 \mathrm{mg}$ administration to every 
other week. ${ }^{52}$ Patients were randomized 1:1 to a standard once-weekly or an extended dose. At the end of an average follow-up of 21 weeks, the rate of remission maintained was $90 \%$ and $86 \%$, respectively, with no statistically significant difference between the two regimens.

Finally, in an observational study in routine clinical practice, the etanercept dose was reduced in $16 \mathrm{AS}$ patients in clinical remission, defined as BASDAI $<4$ and normal C-reactive protein levels. ${ }^{53}$ Different patterns of dose reduction were used: $25 \mathrm{mg}$ weekly in four patients (25\%), $25 \mathrm{mg}$ every 10 days in one patient (6.3\%), $25 \mathrm{mg}$ every other week in two patients, $50 \mathrm{mg}$ every 8 days in three patients (18.7\%), and $50 \mathrm{mg}$ every 10 days in the remaining six patients $(37.5 \%)$. All patients remained on the low-dose regimen after a mean follow-up of $21 \pm 21$ months.

\section{Intra-articular etanercept}

Promising results were obtained in 16 Chinese AS patients receiving computed tomography-guided intra-articular injections of etanercept $25 \mathrm{mg}$ at 0,4 , and 8 weeks. ${ }^{54}$ The longterm efficacy of this new route of administration remains to be demonstrated.

\section{Work disability}

The effectiveness of etanercept in preventing work disability as a result of AS was assessed in a small, double-blind, placebo-controlled, 12-week trial with 40 patients using the Ankylosing Spondylitis Work Instability Scale. ${ }^{55}$ Differences between groups were not statistically significant, probably due to the high rate of long-standing disease and the short duration of the study. However, in another study, etanercept showed improvement in work productivity among AS patients, with an increase in the full-time employment rate of $6.8 \%$ and a decrease in mean number of sick days to 22 days. ${ }^{56}$ Similar results were found with other anti-TNF drugs, ${ }^{57}$ so that the effect of these agents on work participation in real life should be examined further in larger population-controlled studies.

\section{Safety of etanercept in AS}

There are some differences between etanercept and other TNF- $\alpha$ blockers in terms of their mechanism of action. Etanercept does not induce apoptosis in some tissues (eg, the gastrointestinal mucosa), while both anti-TNF- $\alpha$ soluble receptor and monoclonal antibodies seem to cause apoptosis in the synovium. ${ }^{58}$ In contrast with adalimumab or infliximab, etanercept does not activate complement-dependent cytolysis or antibody-dependent cell-mediated cytotoxicity. In fact, etanercept contains the Fc portion of immunoglobulin G1, but does not fix the complement. ${ }^{58}$ The hypothesis of different steric accessibility of the Fc region of etanercept could explain the markedly shorter plasma half-life of etanercept versus monoclonal antibodies. ${ }^{59}$ The above-reported findings could explain some differences in the safety profile of etanercept with respect to infliximab and adalimumab.

\section{Main adverse events}

Data on the safety of etanercept in AS come mainly from randomized clinical trials, observational open-label extensions of randomized clinical trials, registers, and case reports. The highest level of evidence is provided by randomized clinical trials and their meta-analyses, but it is important to remember that the populations included in randomized clinical trials are biased by their selection criteria and could be different in actual clinical practice. The main adverse events recorded during randomized clinical trials and two open-label extensions in patients with AS are summarized in Table 2.

In the randomized clinical trials, the rate of adverse events was similar between the treatment and placebo groups, except for injection site reactions, which were more frequent in the etanercept groups. ${ }^{14,15,17,18}$ In the open-label

Table 2 Main adverse events occurring during treatment with etanercept in patients with ankylosing spondyloarthritis in randomized clinical trials and open-label extensions

\begin{tabular}{|c|c|c|c|c|c|c|c|c|}
\hline \multirow[t]{2}{*}{ Adverse event } & \multicolumn{2}{|l|}{ AS-RCT ${ }^{14}$} & \multicolumn{2}{|l|}{ AS-RCT ${ }^{18}$} & \multicolumn{2}{|l|}{ AS-OLE ${ }^{47}$} & \multirow{2}{*}{$\begin{array}{l}\text { AS-OLE }^{15} \\
\text { ETN } \\
(n=257)\end{array}$} & \multirow{2}{*}{$\begin{array}{l}\text { AS-OLE }{ }^{17} \\
\text { ETN } \\
(n=81)\end{array}$} \\
\hline & $\begin{array}{l}\text { ETN } \\
(n=138)\end{array}$ & $\begin{array}{l}\text { PL } \\
(n=139)\end{array}$ & $\begin{array}{l}\text { ETN } \\
(n=|5|)\end{array}$ & $\begin{array}{l}\text { PL } \\
(n=5 I)\end{array}$ & $\begin{array}{l}\text { ETN TW } \\
(n=54)\end{array}$ & $\begin{array}{l}\text { ETN OW } \\
(n=54)\end{array}$ & & \\
\hline Injection site reactions & $30 \%$ & $9 \%$ & $23 \%$ & $12 \%$ & $7 \%$ & $8 \%$ & $22 \%$ & $37 \%$ \\
\hline Upper respiratory tract infection & $20 \%$ & $12 \%$ & $8 \%$ & $14 \%$ & $5 \%$ & $8 \%$ & $45 \%$ & $53 \%$ \\
\hline Headache & $14 \%$ & $12 \%$ & $4 \%$ & $0 \%$ & $<3 \%$ & $<3 \%$ & $20 \%$ & $20 \%$ \\
\hline Diarrhea & $8 \%$ & $9 \%$ & $4 \%$ & $0 \%$ & $<3 \%$ & $<3 \%$ & $18 \%$ & $15 \%$ \\
\hline Rhinitis & $6 \%$ & $6 \%$ & $<3 \%$ & $<3 \%$ & $<3 \%$ & $<3 \%$ & NA & $14 \%$ \\
\hline Rash & $8 \%$ & $6 \%$ & $<3 \%$ & $<3 \%$ & $<3 \%$ & $<3 \%$ & NA & NA \\
\hline
\end{tabular}

Note: Adapted with permission from D'Angelo S, Palazzi C, Cantini F, Lubrano E, Marchesoni A, Mathieu A. Etanercept in spondyloarthopathies. Part II: safety and pharmacoeconomic issues. Clin Exp Rheumatol. 20I I;29:865-870. ${ }^{89}$

Abbreviations: AS, ankylosing spondylitis; RCT, randomized clinical trials; OLE, open-label extension; ETN, etanercept; PL, placebo; TW, twice a week; OW, once a week. 
extensions, ${ }^{15,17,47}$ the number of etanercept discontinuations because of adverse events was very low. Overall, serious adverse events occurred in less than $5 \%$ of the patients, and were often unrelated to treatment. These results are similar to those reported for other anti-TNF agents in the treatment of AS. However, further studies are needed to compare safety outcomes, especially with respect to long-term follow-up. ${ }^{60}$

The safety of treatment with etanercept in patients with AS at high doses (100 mg per week) was compared with that of a standard dose (50 mg weekly) in LOADET (A 12-week Randomized, Double-blind, Multicenter Pilot Study to Evaluate the Effect of Etanercept $100 \mathrm{mg}$ and $50 \mathrm{mg}$ Weekly in Subjects With Ankylosing Spondylitis). Adult patients with AS were randomized to receive etanercept $50 \mathrm{mg}$ twice a week or etanercept $50 \mathrm{mg}$ once a week for 12 weeks. They concluded that high-dose etanercept in the treatment of AS for 12 weeks is as safe as the standard dose. ${ }^{48}$

In a recent open-label extension involving $59 \mathrm{AS}$ patients treated with etanercept for 264 weeks (original etanercept group) or 252 weeks (original placebo group), serious infections occurred at a rate of 0.03 events per subject years, while no cases of tuberculosis or opportunistic infections were reported. ${ }^{61}$

\section{National registry data}

Post-marketing surveillance and registers are an interesting source of safety data for unselected patient populations. The Spanish register of biologics, BIOBADASER, included 1,524 patients with spondyloarthritis, of whom 657 had AS. ${ }^{62}$ Most of the patients were on infliximab but there was an exposure to etanercept of 134 patient-years for AS. At 3 years, the drug survival rate for all of the three anti-TNF- $\alpha$ agents was 0.76 for AS and 0.73 for psoriatic arthritis, with adverse events responsible for $45.4 \%$ of therapy discontinuations. The adverse event incidence rate per 100 patient-years of exposure in all of the 507 patients with spondyloarthritis treated with etanercept was less than 1.0, with the exception of the infection rate, which was only 1.01 .

A Norwegian register of DMARD and biologic therapy prescriptions collected 249 patients with AS (among other diseases) receiving a TNF- $\alpha$ antagonist. For 122 of these patients, etanercept was the first biologic. ${ }^{25}$ The one-year withdrawal rate for this drug was $24.6 \%$. Adverse events were responsible for $69.2 \%$ and $43.6 \%$ of discontinuations of anti-TNF- $\alpha$ agents in psoriatic arthritis and AS, respectively.

Our group conducted an observational study comparing the duration of treatment with etanercept with that of the rest of the biologic drugs in our cohort of patients on biologic therapy ${ }^{63}$ We included 205 patients on biologic treatment, 92 patients on treatment with etanercept, $33 \%$ of whom had AS. Adverse events as a cause of discontinuation of etanercept occurred in 15 patients $(16 \%)$.

In conclusion, the data from existing registers seem to indicate that in standard clinical settings of patients with AS, anti-TNF- $\alpha$ agents, and etanercept in particular, are more often responsible for drug discontinuation than in randomized clinical trials but, nevertheless, these molecules have a good safety profile.

Reactivation of tuberculosis, reactivation of hepatitis B virus infection, congestive heart failure, demyelinating neurologic disorders, hematologic disorders like aplastic anemia or pancytopenia, vasculitis, immunogenicity, and exacerbation or induction of psoriasis are class effects seen with all of the TNF- $\alpha$ inhibitors, and have been seen in patients with rheumatoid arthritis and those with spondyloarthritis. ${ }^{64,65}$

\section{Reactivation of tuberculosis}

The number of tuberculosis cases decreased after institution of tuberculosis screening, but the problem has not disappeared completely. Since the screening test may produce false negative results and first infection during etanercept treatment may occur, careful vigilance and repeat screening for tuberculosis has been suggested. ${ }^{66}$ It has been confirmed that etanercept is less likely to reactivate tuberculosis than the other TNF- $\alpha$ antagonists. ${ }^{67,68}$ In addition, etanercept did not induce any reactivation of tuberculosis in a cohort of 84 patients, including those with AS or psoriatic arthritis or those at high risk for tuberculosis infections (purified protein derivative-positive patients). ${ }^{69}$ An interesting point is the relationship between TNF- $\alpha$ blockers and production of interferon- $\gamma$. In fact, interferon- $\gamma$ expression was inhibited by infliximab, but not by etanercept, ${ }^{70,71}$ suggesting that the risk of granuloma-dependent infection may reflect an ability to inhibit both TNF- $\alpha$ and (indirectly) interferon- $\gamma{ }^{58}$

\section{Hepatitis B virus, hepatitis $C$ virus, and human immunodeficiency virus}

Reactivation of hepatitis B virus, congestive heart failure, and demyelinating diseases are potential adverse events of anti-TNF- $\alpha$ therapy that can occur regardless of the underlying condition. Vasculitis is much more likely to occur in patients with rheumatoid arthritis than in those with spondyloarthritis. ${ }^{72,73}$ Treatment with etanercept in the setting of chronic hepatitis $\mathrm{C}$ virus infection seems to be safe, but 
the relevant data are obtained mainly from studies of patients with rheumatoid arthritis. ${ }^{64,74}$

The safety of etanercept in human immunodeficiency virus (HIV)-positive patients has also been studied. There are published retrospective series of HIV-positive patients with rheumatoid arthritis, spondyloarthritis, or psoriasis treated with anti-TNF drugs (including etanercept). These studies suggest that treatment with anti-TNF- $\alpha$ therapy is a viable alternative for HIV patients without advanced disease but with associated rheumatic diseases refractory to standard therapy. ${ }^{75,76}$

\section{Immunogenicity}

It has been suggested that etanercept might be less immunogenic than the other TNF- $\alpha$ antagonists, especially in AS. ${ }^{73,77}$ Immunogenicity, specifically the onset of antibodies against TNF-blocking agents, seems to play an important role in lack of response to treatment with these drugs. ${ }^{78}$ Some studies in patients with rheumatoid arthritis have demonstrated that lower etanercept levels were associated with lack of response, ${ }^{79,80}$ and antibodies against etanercept, all non-neutralizing, were obtained in less than $2 \%$ of the patients. ${ }^{81}$ The relationship of clinical response in AS with etanercept levels and the presence of antibodies to etanercept was recently assessed in 53 consecutive patients. ${ }^{77}$ All patients with AS had detectable etanercept levels, regardless of whether they were responders or non-responders. In contrast with previous studies of other TNF-blocking agents, no antibodies against etanercept were detected in any of the assays. This study indicates that immunogenicity does not play an important role in explaining the non-response of patients with AS to treatment with etanercept. ${ }^{77}$

\section{Paradoxical psoriasis}

Exacerbation or induction of psoriasis is a paradoxical effect of TNF- $\alpha$ inhibition that is not specific to AS, and has been reported in other diseases. ${ }^{65}$ The scientific evidence in this regard suggests that while the anti-TNF- $\alpha$ monoclonal antibodies can induce new-onset psoriasis, etanercept is more likely to cause flare-ups of existing disease. ${ }^{82}$

\section{Malignancy}

The relationship between malignancy and anti-TNF- $\alpha$ drugs is an unresolved concern. In rheumatoid arthritis, some studies did not find an increased incidence of lymphoma or solid cancers in patients taking TNF- $\alpha$ inhibitors, while others did. ${ }^{83}$ In a recent systematic review, patients with psoriatic arthritis or psoriasis treated with anti-TNF agents showed increased rates of non-melanoma skin cancer. ${ }^{84}$ This risk was increased by treatment with methotrexate, cyclosporine, and phototherapy.

A recent meta-analysis of registries and a systematic review of long-term extension studies did not reveal an increased risk of malignancy in patients with rheumatoid arthritis receiving anti-TNF therapy. ${ }^{85}$ The pooled odds ratio for total malignancy and for non-melanoma skin cancers was 0.81 (95\% confidence interval [CI] $0.71-0.94)$ and 0.79 (95\% CI 0.62-1.02) in an TNF-antagonist group versus a DMARD group, respectively. Among four long-term studies and four registries, no significant increase in incidence of total malignancy was noted versus the general population. Only an increased risk of non-melanoma skin cancers was found. The presence of many confounding factors, the low rate of malignancies, and the long length of time needed for a cancer to develop complicate the search for an answer to this question. Although the data on malignancy in patients with spondyloarthritis treated with anti-TNF agents are scant, the strong immunosuppressive effect of these drugs implies a potential risk of cancer.

\section{Acute uveitis, Crohn's disease, and sarcoidosis}

Acute uveitis, Crohn's disease, and sarcoidosis are other adverse events that have been rarely associated with etanercept therapy in AS patients. Several anecdotal reports and a study using observations from two drug event databases have suggested that etanercept may be responsible for flare-ups or new occurrences of acute anterior uveitis. ${ }^{86}$ In contrast, other data have shown that etanercept may prevent acute uveitis in AS, although less effectively than infliximab. ${ }^{87}$

In this regard, a systematic review of the literature was recently conducted in order to analyze the effectiveness of immunosuppressants and biologic therapies in patients with autoimmune posterior uveitis, chronic anterior uveitis associated with juvenile idiopathic arthritis, and macular edema. The authors concluded that biologic therapies (except for etanercept and daclizumab in Behcet's disease) are beneficial for the treatment of autoimmune uveitis. They did not consider etanercept to be as effective in autoimmune uveitis, as per recommendation A, evidence level $1 \mathrm{~b} .{ }^{88}$ Therefore, considering all the available data, it seems likely that etanercept is not as effective as the anti-TNF- $\alpha$ monoclonal antibodies in treating and preventing acute uveitis. ${ }^{89}$

Unlike the other two TNF- $\alpha$ inhibitors, etanercept is not effective in controlling active Crohn's disease. ${ }^{40}$ In fact, newonset Crohn's disease has been described in AS patients with 
etanercept.${ }^{90}$ Crohn's disease may be considered an immunemediated injury induced by etanercept, but the causative role of etanercept has not been demonstrated at this point.

Paradoxical development of sarcoidosis in patients on etanercept therapy has been reported in patients with spondyloarthritis. ${ }^{87,91,92}$

\section{Geriatric patients}

An interesting issue regarding the safety profile of etanercept therapy is its use in geriatric patients, who may be more prone to develop adverse events. However, elderly patients are usually excluded from randomized clinical trials. A retrospective analysis of trials with etanercept in rheumatoid arthritis, AS, and psoriatic arthritis, has shown that for patients $\geq 65$ years, the rate of adverse events and serious adverse events was not higher than for younger patients. ${ }^{93}$

\section{Pregnancy}

Neither animal studies nor prospective, controlled human studies have shown an increased rate of adverse outcomes after exposure to etanercept during pregnancy. ${ }^{94}$ Nevertheless, their use during pregnancy is still controversial, because it remains unclear whether the benefits of treatment might be outweighed by potential teratogenicity or adverse effects on the course of pregnancy. Based on the available literature, experts suggest that continuation of treatment with TNF- $\alpha$ blockers is justified in pregnant patients with high disease activity and disease progression. ${ }^{95-97}$

\section{Fertility and breast-feeding}

There are scarce data in the literature in regard to fertility in AS patients treated with etanercept, but we can find indirect evidence from some studies. The effect of TNF- $\alpha$ and TNF- $\alpha$ antagonists on semen quality in men is controversial. One study reported that infliximab infusion did not affect semen volume, sperm concentration, or forward progression, but that it did decrease sperm motility and the percentage of normal oval forms. ${ }^{98}$ However, in another study done with sperm suspensions incubated with different doses of TNF- $\alpha$, TNF- $\alpha$ plus infliximab, and infliximab alone, sperm motility and membrane integrity were higher in the samples incubated with TNF- $\alpha$ plus infliximab than in the samples treated with TNF- $\alpha$ or infliximab alone. This study demonstrates that exposing spermatozoa to increased concentrations of TNF- $\alpha$ results in a loss of functional and genomic spermatozoa integrity and that infliximab is capable of reversing the toxic effects induced by TNF- $\alpha .{ }^{99}$ Since the effects of possible transfer of etanercept to maternal milk in a still immature immune system are not known, in accordance with the risk/ benefit principle, the use of etanercept is not recommended in breast-feeding women. ${ }^{100}$

\section{Conclusion}

In the 12 years since commercialization of etanercept, its efficacy has been confirmed in AS, as shown in randomized clinical trials, open-label extension studies, and national registries. Etanercept is effective in different manifestations of the disease, including back pain, peripheral arthritis, enthesitis, and psoriasis. However, etanercept has shown no efficacy in inflammatory bowel disease, and its efficacy in the treatment of uveitis appears to be lower than that of the other anti-TNF drugs. Other aspects of AS, like radiographic progression, remain to be clarified in the future, since all the available anti-TNF agents have not shown efficacy in this regard to date. In the current economic crisis, etanercept has proved to be a useful drug, is able to maintain high rates of clinical remission when extending dosing intervals, and is efficacious when readministered after discontinuation of treatment. Regarding safety, up to 5 years of data from randomized clinical trials, open-label extensions, registries, and meta-analysis show that continuous long-term treatment with etanercept has a favorable risk-benefit ratio and no cumulative toxicity.

\section{Acknowledgments}

The findings are presented here with grant support from and on behalf of the AIRE-MB (Asociación para la Investigación en Reumatología de la Marina Baixa) group: José Rosas, Esteban Salas, José Miguel Senabre-Gallego, Gregorio Santos-Soler, Catalina Cano, Marisa Lorente, AnaPons, Rheumatology, Hospital Marina Baixa, Villajoyosa, Spain; Francisca LLinares-Tello, Juan Molina, Laboratory Department, Hospital Marina Baixa, Villajoyosa, Spain; Carlos Santos-Ramírez, Reumatology, Hospital Marina Salud, Denia, Spain; Xavier Barber, Universidad Miguel Hernández, Elche, Spain; Mabel Sánchez-Barrioluengo, Universitat Politècnica de València, Valencia, Spain.

\section{Disclosure}

The authors report no conflicts of interest in this work.

\section{References}

1. Carmona-Ortells L, Loza-Santamaría E; grupo ESPOGUIA Management of spondyloarthritis (ESPOGUIA): methodology and general data from the document. Reumatol Clin. 2010;6 Suppl 1:1-5.

2. Hukuda S, Minami M, Saito T, et al. Spondyloarthropathies in Japan: nationwide questionnaire survey performed by the Japan Ankylosing Spondylitis Society. J Rheumatol. 2001;28:554-559. 
3. van der Heijde D, Landewé R, Einstein S, et al. Radiographic progression of ankylosing spondylitis after up to two years of treatment with etanercept. Arthritis Rheum. 2008;58:1324-1331.

4. van der Heijde D, Sieper J, Maksymowych WP, et al; Assessment of SpondyloArthritis international Society. 2010 Update of the international ASAS recommendations for the use of anti-TNF agents in patients with axial spondyloarthritis. Ann Rheum Dis. 2011;70:905-908.

5. Garrett S, Jenkinson T, Kennedy LG, Whitelock H, Gaisford P, Calin A. A new approach to defining disease status in ankylosing spondylitis: the Bath Ankylosing Spondilytis Disease Activity Index. J Rheumatol. 1994;21:2286-2291.

6. Calin A, Garrett S, Whitelock H, et al. A new approach to defining functional ability in ankylosing spondylitis: the development of the Bath Ankylosing Spondylitis Functional Index. J Rheumatol. 1994;21:2281-2285.

7. Jenkinson TR, Mallorie PA, Whitelock H, Kennedy LG, Garrett S, Calin A. Defining spinal mobility in ankylosing spondylitis (AS): the Bath AS Metrology Index. J Rheumatol. 1994;21:1694-1698.

8. Anderson JJ, Baron G, Van der Heijde D, Felson DT, Dougados M. Ankylosing spondylitis assessment group preliminary definition of short-term improvement in ankylosing spondylitis. Arthritis Rheum. 2001;44:1876-1886.

9. van der Heijde D, Lie E, Kvien TK, et al. ASDAS, a highly discriminatory ASAS endorsed disease activity score in patients with ankylosing spondylitis. Ann Rheum Dis. 2009;68:1811-1818.

10. Gorman JD, Sack KE, Davis JC Jr. Treatment of ankylosing spondylitis by inhibition of tumor necrosis factor alpha. N Engl J Med. 2002;346: 1349-1356.

11. Davis JC, Webb A, Lund S, Sack K. Results from an open-label extension study of etanercept in ankylosing spondylitis. Arthritis Rheum. 2004;52:302-304.

12. Brandt J, Khariouzov A, Listing J, et al. Six-month results of a double-blind, placebo-controlled trial of etanercept treatment in patients with active ankylosing spondylitis. Arthritis Rheum. 2003;48: 1667-1675.

13. Brandt J, Listing J, Haibel H, et al. Long-term efficacy and safety of etanercept after readministration in patients with active ankylosing spondylitis. Rheumatology (Oxford). 2005;44:342-348.

14. Davis JC, van der Heijde D, Braun J, et al. Recombinant human tumor necrosis factor (etanercept) for treating ankylosing spondylitis: a randomized controlled trial. Arthritis Rheum. 2003;48:3230-3236.

15. Davis JC, van der Heijde D, Braun J, et al. Efficacy and safety of up to 192 weeks of etanercept therapy in patients with ankylosing spondylitis. Ann Rheum Dis. 2008;67:346-352.

16. Calin A, Dijkmans BA, Emery P, et al. Outcomes of a multicentre randomised clinical trial of etanercept to treat ankylosing spondylitis. Ann Rheum Dis. 2004;63:1594-600.

17. Dijkmans BAC, Emery P, Hakala M, et al. Etanercept in the long-term treatment of patients with ankylosing spondylitis. J Rheumatol. 2009;36: 1256-1264.

18. van der Heijde D, Da Silva JC, Dougados M, et al. Etanercept $50 \mathrm{mg}$ once weekly is as effective as $25 \mathrm{mg}$ twice weekly in patients with ankylosing spondylitis. Ann Rheum Dis. 2006;65:1572-1577.

19. Braun J, McHugh N, Singh A, Wajdula JS, Sato R. Improvement in patient-reported outcomes for patients with ankylosing spondylitis treated with etanercept $50 \mathrm{mg}$ once-weekly and $25 \mathrm{mg}$ twice-weekly. Rheumatology (Oxford). 2007;46:999-1004.

20. Braun J, van der Horst-Bruinsma IE, Huang F, et al. Clinical efficacy and safety of etanercept versus sulfasalazine in patients with ankylosing spondylitis: a randomized, double-blind trial. Arthritis Rheum. 2011;63: 1543-1551.

21. Li ZH, Zhang Y, Wang J, Shi ZJ. Etanercept in the treatment of ankylosing spondylitis: a meta-analysis of randomized, double-blind, placebo-controlled clinical trials, and the comparison of the Caucasian and Chinese population. Eur J Orthop Surg Traumatol. 2013;23: 497-506.
22. McLeod C, Bagust A, Boland A, et al. Adalimumab, etanercept and infliximab for the treatment of ankylosing spondylitis: a systematic review and economic evaluation. Health Technol Assess. 2007;11: $1-158$, iii-iv.

23. Nell-Duxneuner V, Schroeder Y, Reichardt B, Bucsics A. The use of TNF-inhibitors in ankylosing spondylitis in Austria from 2007 to 2009 - a retrospective analysis. Int J Clin Pharmacol Ther. 2012;50: $867-872$.

24. Glintborg B, Ostergaard M, Krogh NS, Dreyer L, Kristensen HL, Hetland ML. Predictors of treatment response and drug continuation in 842 patients with ankylosing spondylitis treated with antitumour necrosis factor: results from 8 years' surveillance in the Danish nationwide DANBIO registry. Ann Rheum Dis. 2010;69: 2002-2008

25. Heiberg MS, Koldingsnes W, Mikkelsen K, et al. The comparative oneyear performance of anti-tumor necrosis factor alpha drugs in patients with rheumatoid arthritis, psoriatic arthritis, and ankylosing spondylitis: results from a longitudinal, observational, multicenter study. Arthritis Rheum. 2008;15;59:234-240.

26. Pavelka K, Forejtová S, Stolfa J, et al. Anti-TNF therapy of ankylosing spondylitis in clinical practice. Results from the Czech national registry ATTRA. Clin Exp Rheumatol. 2009;27:958-963.

27. Coates LC, Cawkwell LS, Ng NW, et al. Real life experience confirms sustained response to long-term biologics and switching in ankylosing spondylitis. Rheumatology (Oxford). 2008;47:897-900.

28. Conti F, Ceccarelli F, Marocchi E, et al. Switching tumour necrosis factor alpha antagonists in patients with ankylosing spondylitis and psoriatic arthritis: an observational study over a 5-year period. Ann Rheum Dis. 2007;66:1393-1397.

29. Delaunay C, Farrenq V, Marini-Portugal A, Cohen JD, Chevalier X, Claudepierre P. Infliximab to etanercept switch in patients with spondyloarthropathies and psoriatic arthritis: preliminary data. J Rheumatol. 2005;32:2183-2185.

30. Rudwaleit M, van der Heijde D, Landewé R, et al. The development of Assessment of Spondyloarthritis International Society classification criteria for axial spondyloarthritis (part II): validation and final selection. Ann Rheum Dis. 2009;68:77-83.

31. Haibel H, Rudwaleit M, Listing J, et al. Efficacy of adalimumab in the treatment of axial spondylarthritis without radiographically defined sacroiliitis: results of a twelve week randomized, double-blind, placebo-controlled trial followed by an open-label extension up to week fifty-two. Arthritis Rheum. 2008;58:1981-1991.

32. Barkham N, Keen HI, Coates LC, et al. Clinical and imaging efficacy of infliximab in HLA-B27-positive patients with magnetic resonance imaging-determined early sacroiliitis. Arthritis Rheum. 2009;60: 946-954.

33. Song IH, Hermann K, Haibel H, et al. Effects of etanercept versus sulfasalazine in early axial spondyloarthritis on active inflammatory lesions as detected by whole-body MRI (ESTHER): a 48-week randomized controlled trial. Ann Rheum Dis. 2011;70:590-596.

34. Dougados M, van der Heijde D, Sieper J, et al. Clinical and imaging efficacy of etanercept in early non-radiographic axial spondyloarthritis: a 12-week, randomized, double-blind, placebo-controlled trial. Abstract OP0108 presented at the European League Against Rheumatism Annual Congress, Madrid, Spain, June 12-15, 2013.

35. Dougados M, Braun J, Szanto S, et al. Efficacy of etanercept on rheumatic signs and pulmonary function tests in advanced ankylosing spondylitis: results of a randomised double-blind placebo-controlled study (SPINE). Ann Rheum Dis. 2011;70:799-804.

36. Dougados M, Braun J, Szanto S, et al. Continuous efficacy of etanercept in severe and advanced ankylosing spondylitis: results from a 12-week open-label extension of the SPINE study. Rheumatology (Oxford). 2012;51:1687-1696.

37. Leonardi CL, Powers JL, Matheson RT, et al; Etanercept Psoriasis Study Group. Etanercept as monotherapy in patients with psoriasis. N Engl J Med. 2003;349:2014-2022. 
38. Mease PJ, Goffe BS, Metz J, Vanderstoep A, Finck B, Burge DJ. Etanercept in the treatment of psoriatic arthritis and psoriasis; a randomised trial. Lancet. 2000;356:385-390.

39. Mease PJ, Kivitz AJ, Burch FX, et al. Etanercept treatment of psoriatic arthritis. Safety, efficacy, and effect on disease progression. Arthritis Rheum. 2004;50:2264-2272.

40. Sandborn WJ, Hanauer SB, Katz S, et al. Etanercept for active Crohn's disease: a randomized, double-blind, placebo-controlled trial. Gastroenterology. 2001;121:1088-1094.

41. Braun J, Pavelka K, Ramos-Remus C, et al. Clinical efficacy of etanercept versus sulfasalazine in ankylosing spondylitis subjects with peripheral joint involvement. J Rheumatol. 2012;39:836-840.

42. Wang D, Ma L, Wu D. Efficacy of etanercept in ankylosing spondylitis hip lesions. Joint Bone Spine. 2011;78:531-532.

43. Baraliakos X, Davis J, Tsuji W, Braun J. Magnetic resonance imaging examinations of the spine in patients with ankylosing spondylitis before and after therapy with the tumor necrosis factor alpha receptor fusion protein etanercept. Arthritis Rheum. 2005;52:1216-1223.

44. Rudwaleit M, Baraliakos X, Listing J, Brandt J, Sieper J, Braun J. Magnetic resonance imaging of the spine and the sacroiliac joints in ankylosing spondylitis and undifferentiated spondyloarthritis during treatment with etanercept. Ann Rheum Dis. 2005;64:1305-1310.

45. Creemers MC, Franssen MJ, van't Hof MA, Gribnau FW, van de Putte LB, van Riel PL.Assessment of outcome in ankylosing spondylitis: an extended radiographic scoring system. Ann Rheum Dis. 2005;64:127-129.

46. Baraliakos X, Haibel H, Listing J, Sieper J, Braun J. Continuous longterm anti-TNF therapy does not lead to an increase in the rate of new bone formation over 8 years in patients with ankylosing spondylitis Ann Rheum Dis. March 27, 2013. [Epub ahead of print.]

47. van der Heijde D, Salonen D, Weissman BN, et al. Assessment of radiographic progression in the spines of patients with ankylosing spondylitis treated with adalimumab for up to 2 years. Arthritis Res Ther. 2009;11:R127.

48. Navarro-Sarabia F, Fernández-Sueiro JL, Torre-Alonso JC, et al. High-dose etanercept in ankylosing spondylitis: results of a 12-week randomized, double blind, controlled multicentre study (LOADET study). Rheumatology (Oxford). 2011;50:1828-1837.

49. Lee SH, Lee YA, Hong SJ, Yang HI. Etanercept $25 \mathrm{mg} /$ week is effective enough to maintain remission for ankylosing spondylitis among Korean patients. Clin Rheumatol. 2008;27:179-181.

50. Song IH, Althoff CE, Haibel H, et al. Frequency and duration of drug-free remission after 1 year of treatment with etanercept versus sulfasalazine in early axial spondyloarthritis: 2 year data of the ESTHER trial. Ann Rheum Dis. 2012;71:1212-1215.

51. Lee J, Noh JW, Hwang JW, et al. Extended dosing of etanercept $25 \mathrm{mg}$ can be effective in patients with ankylosing spondylitis: a retrospective analysis. Clin Rheumatol. 2010;29:1149-1154.

52. Cantini F, Niccoli L, Cassarà E, Kaloudi O, Nannini C. Duration of remission after halving of the etanercept dose in patients with ankylosing spondylitis: a randomized, prospective, long-term, follow-up study. Biologics. 2013;7:1-6.

53. Navarro-Compán V, Moreira V, Ariza-Ariza R, Hernández-Cruz B, Vargas-Lebrón C, Navarro-Sarabia F. Low doses of etanercept can be effective in ankylosing spondylitis patients who achieve remission of the disease. Clin Rheumatol. 2011;30:993-996.

54. Cui Y, Xiao Z, Shuxia W, et al. Computed tomography guided intraarticular injection of etanercept in the sacroiliac joint is an effective mode of treatment of ankylosing spondylitis. Scand J Rheumatol. 2009;27:958-963.

55. Barkham N, Coates LC, Keen H, et al. Double-blind placebo-controlled trial of etanercept in the prevention of work disability in ankylosing spondylitis. Ann Rheum Dis. 2010;69:1926-1928.

56. Moots RJ, Ostor AJ, Loft AG, et al. Reduction of direct and indirect costs in patients with AS receiving etanercept: results from an open-label 36-week extension of the ASCEND study in four European countries. Rheumatology (Oxford). 2012;51:393-396.
57. van der Burg LR, Ter Wee MM, Boonen A. Effect of biological therapy on work participation in patients with ankylosing spondylitis: a systematic review. Ann Rheum Dis. 2012;71:1924-1933.

58. Furst DE, Wallis R. Broder M, Beenhouwer DO. Tumor necrosis factor antagonists: different kinetics and/or mechanisms of acting may explain differences in the risk for developing granulomatous infection. Semin Arthritis Rheum. 2006;36:159-167.

59. Tracey D, Klareskog L, Sasso EH, Salfeld JG, Tak PP. Tumor necrosis factor antagonist mechanisms of action: a comprehensive review. Pharmacol Ther. 2008;117:244-279.

60. Machado MA, Barbosa MM, Almeida AM, et al. Treatment of ankylosing spondylitis with TNF blockers: a meta-analysis. Rheumatol Int. May 18, 2013. [Epub ahead of print.]

61. Martín-Mola E, Sieper J, Leirisalo-Repo M, et al. Sustained efficacy and safety, including patient-reported outcomes, with etanercept treatment over 5 years in patients with AS. Clin Exp Rheumatol. 2010;28: 238-245.

62. Carmona L, Gómez-Reino JJ; BIOBADASER Group. Survival of TNF antagonists in spondylarthritis is better than in rheumatoid arthritis. Data from the Spanish registry BIOBADASER. Arthritis Res Ther. 2006;8:R72.

63. Senabre-Gallego JM, Rosas-Gómez de Salazar J, Santos-Soler G, et al. Duration of treatment with etanercept and motives for discontinuation in a cohort of patients with rheumatic disease. Reumatol Clin. 2011;7: 385-388.

64. Desai SB, Furst DE. Problems encountered during anti-tumour necrosis factor therapy. Best Pract Res Clin Rheumatol. 2006;20:757-790.

65. Grinblat B, Scheinberg M. The enigmatic development of psoriasis and psoriasiform lesions during anti-TNF therapy: a review. Semin Arthritis Rheum. 2008;37:251-255.

66. Santos-Ramírez C, Rosas J, Senabre JM, et al. Es necesario repetir la prueba de tuberculina en los pacientes en tratamiento biológico? Resultados preliminares en una cohorte local de pacientes con artropatía inflamatoria. [Is it necessary to repeat the tuberculin test in patients on biological treatment? Preliminary results on a local cohort of patients with inflammatory arthropathy.] Rev Sociedad Val Reuma. 2011;2:15-16. Spanish.

67. Tubach F, Salmon D, Ravaud P, et al. Risk of tuberculosis is higher with anti-tumor necrosis factor monoclonal antibody therapy than with soluble tumor necrosis factor receptor therapy: the three-year prospective French Research Axed on Tolerance of Biotherapies registry. Arthritis Rheum. 2009;60:1884-1894.

68. Dixon WG, Hyrich KL, Watson KD, Lunt M, Galloway J, Ustianowski A. Drug-specific risk of tuberculosis in patients with rheumatoid arthritis treated with anti-TNF therapy: results from the British Society for Rheumatology Biologics Register (BSRBR). Ann Rheum Dis. 2010;69: 522-528.

69. Aggarwal R, Manadan AM, Poliyedath A, Sequeira W, Block JA. Safety of etanercept in patients at high risk for mycobacterial tuberculosis infections. J Rheumatol. 2009;36:914-917.

70. Zou J, Rudwaleit M, Brandt J, Thiel A, Braun J, Sieper J. Up regulation of the production of tumour necrosis factor alpha and interferon gamma by $\mathrm{T}$ cells in ankylosing spondylitis during treatment with etanercept. Ann Rheum Dis. 2003;62:561-564.

71. Zou J, Rudwaleit M, Brandt J, Thiel A, Braun J, Sieper J. Downregulation of the nonspecific and antigen-specific $\mathrm{T}$ cell cytokine response in ankylosing spondylitis during treatment with infliximab. Arthritis Rheum. 2003;48:780-790.

72. Saint Marcoux B, De Bandt M; CRI (Club Rhumatismes et Inflammation). Vasculitides induced by TNF alpha antagonists: a study in 39 patients in France. Joint Bone Spine. 2006;73:710-713.

73. Bacquet-Deschryver H, Jouen F, Quillard M, et al. Impact of three anti-TNF alpha biologics on existing and emergent autoimmunity in rheumatoid arthritis and spondylarthropathy patients. J Clin Immunol. 2008;28:445-455.

74. Brunasso AM, Puntoni M, Gulia A, Massone C. Safety of anti-tumour necrosis factor agents in patients with chronic hepatitis $\mathrm{C}$ infection: a systematic review. Rheumatology (Oxford). 2011;50:1700-1711. 
75. Cepeda EJ, Williams FM, Ishimori ML, Weisman MH, Reveille JD. The use of anti-tumour necrosis factor therapy in HIV-positive individuals with rheumatic disease. Ann Rheum Dis. 2008;67:710-712.

76. Lee ES, Heller MM, Kamangar F, Park KK, Koo JY. Long-term etanercept use for severe generalized psoriasis in an HIV-infected individual: a case study. J Drugs Dermatol. 2012;11:413-414.

77. De Vries MK, Van Der Horst-Bruinsma IE, Nurmohamed M, et al. Immunogenicity does not influence treatment with etanercept in patients with ankylosing spondylitis (AS). Ann Rheum Dis. 2009;68: 531-535.

78. Wolbink GJ, Aarden LA, Dijkmans BA. Dealing with immunogenicity of biologicals: assessment and clinical relevance. Curr Opin Rheumatol. 2009;21:211-215.

79. Jamnitski A, Krieckaert CL, Nurmohamed MT, et al. Patients nonresponding to etanercept obtain lower etanercept concentrations compared with responding patients. Ann Rheum Dis. 2012;71:88-91.

80. Daïen CI, Daïen V, Parussini E. Etanercept concentration in patients with rheumatoid arthritis and its potential influence on treatment decisions: a pilot study. J Rheumatol. 2012;39:1533-1538.

81. Dore RK, Mathews S, Schechtman J, et al. The immunogenicity, safety, and efficacy of etanercept liquid administered once weekly in patients with rheumatoid arthritis. Clin Exp Rheumatol. 2007;25:40-46.

82. Fiorentino DF. The yin and yang of TNF-alpha inhibition. Arch Dermatol. 2007;143:233-236.

83. Furst DE, Keystone EC, Kirkham B, et al. Updated consensus statement on biological agents for the treatment of rheumatic diseases, 2008. Ann Rheum Dis. 2008;67 Suppl 3:iii2-iii25.

84. Krathen MS, Gottlieb AB, Mease PJ. Pharmacologic immunomodulation and cutaneous malignancy in rheumatoid arthritis, psoriasis, and psoriatic arthritis. J Rheumatol. 2010;37:2205-2215.

85. Le Blay P, Mouterde G, Barnetche T, Morel J, Combe B. Risk of malignancy including non-melanoma skin cancers with anti-tumor necrosis factor therapy in patients withrheumatoid arthritis: meta-analysis of registries and systematic review of long-term extension studies. Clin Exp Rheumatol. 2012;30:756-764.

86. Lim LL, Fraunfelder FW, Rosenbaum JT. Do tumor necrosis factor inhibitors cause uveitis? A registry-based study. Arthritis Rheum. 2007; 56:3248-3252.

87. Javot L, Tala S, Scala-Bertola J, et al. Sarcoidosis and anti-TNF: a paradoxical class effect? Analysis of the French Pharmacovigilance system database and literature review. Therapie. 2011;66:149-154. French.
88. Pato E, Muñoz-Fernández S, Francisco F, et al. Systematic review on the effectiveness of immunosuppressants and biological therapies in the treatment of autoimmune posterior uveitis. Semin Arthritis Rheum. 2011;40:314-323.

89. D’Angelo S, Palazzi C, Cantini F, Lubrano E, Marchesoni A, Mathieu A. Etanercept in spondyloarthopathies. Part II: safety and pharmacoeconomic issues. Clin Exp Rheumatol. 2011;29:865-870.

90. Mrabet D, Selmi A, Filali A, Sahli H, Sellami S. Onset of Crohn's disease induced by etanercept therapy: a case report. Rev Med Liege. 2012;67:619-622. French.

91. González-López MA, Blanco R, González-Vela MC, FernándezLlaca H, Rodríguez-Valverde V. Development of sarcoidosis during etanercept therapy. Arthritis Rheum. 2006;55:817-820.

92. Lamrock E, Brown P. Development of cutaneous sarcoidosis during treatment with tumour necrosis alpha factor antagonists. Australas $J$ Dermatol. 2012;53:e87-e90.

93. Fleischmann R, Iqbal I. Risk:benefit profile of etanercept in elderly patients with rheumatoid arthritis, ankylosing spondylitis or psoriatic arthritis. Drugs Aging. 2007;24:239-254.

94. Scioscia C, Scioscia M, Anelli MG, Praino E, Bettocchi S, Lapadula G. Intentional etanercept use during pregnancy for maintenance of remission in rheumatoid arthritis. Clin Exp Rheumatol. 2011;29: 93-95.

95. Østensen M, Förger F. Management of RA medications in pregnant patients. Nat Rev Rheumatol. 2009;5:382-390.

96. Østensen M, Lockshin M, Doria A, Valesini G, Meroni P, Gordon C. Update on safety during pregnancy of biological agents and some immunosuppressive anti-rheumatic drugs. Rheumatology (Oxford). 2008;47 Suppl 3:iii28-iii31.

97. Rump JA, Schönborn H. Conception and course of eight pregnancies in five women on TNF blocker etanercept treatment. Z Rheumatol. 2010;69:903-909.

98. Mahadevan U, Terdiman JP, Aron J, Jacobsohn S, Turek P. Infliximab and semen quality in men with inflammatory bowel disease. Inflamm Bowel Dis. 2005;11:395-399.

99. Said TM, Agarwal A, Falcone T, Sharma RK, Bedaiwy MA, Li L. Infliximab may reverse the toxic effects induced by tumor necrosis factor alpha in human spermatozoa: an in vitro model. Fertil Steril. 2005;83:1665-1673.

100. Borrego L. Etanercept in pregnancy and breast-feeding. Actas Dermosifiliogr. 2010;101 Suppl 1:97-101.
Patient Preference and Adherence

\section{Publish your work in this journal}

Patient Preference and Adherence is an international, peer-reviewed, open access journal focusing on the growing importance of patient preference and adherence throughout the therapeutic continuum. Patient satisfaction, acceptability, quality of life, compliance, persistence and their role in developing new therapeutic modalities and compounds to
Dovepress

optimize clinical outcomes for existing disease states are major areas of interest. This journal has been accepted for indexing on PubMed Central. The manuscript management system is completely online and includes a very quick and fair peer-review system. Visit http://www.dovepress.com/ testimonials.php to read real quotes from published authors. 